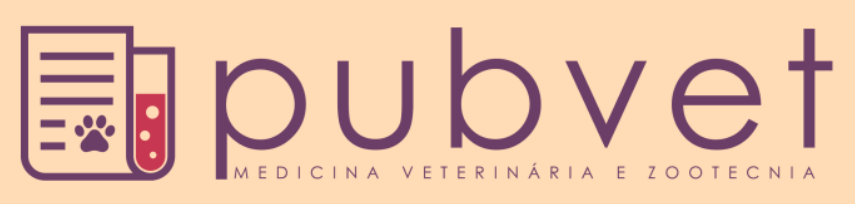

HTTP://DX.DOI.ORG/10.22256/PUBVET.V11N10.991-995

\title{
Colisepticemia em Pinguim-de-Magalhães Magellanicus) com bumblefoot: Relato de caso
}

\author{
Luiza da Gama Osório ${ }^{1 *}$, Anna Luiza Silva ${ }^{1}$, Sílvia Regina Leal Ladeira ${ }^{1}$, Mauro Pereira \\ Soares $^{1}$, Ângela Leitzke Cabana ${ }^{2}$, Melissa Orzeschovski Xavier ${ }^{3}$, Rodolfo Pinho Silva- \\ Filho $^{4}$, João Roberto Braga Mello ${ }^{5}$, Renata Osório de Faria ${ }^{1}$, Mário Carlos Araújo \\ Meireles $^{1}$
}

${ }^{1}$ Universidade Federal de Pelotas. ${ }^{2}$ Médica Veterinária Autônoma. ${ }^{3}$ Universidade Federal do Rio Grande $;{ }^{4}$ Centro de Recuperação de Animais Marinhos. ${ }^{5}$ Universidade Federal do Rio Grande do Sul, Brasil. *Autor para correspondência, E-mail: luizaosorio@yahoo.com

\begin{abstract}
RESUMO. Pododermatite, ou bumblefoot, é uma afecção podal limitante à reabilitação de pinguins. O estudo relata um caso de septicemia por Escherichia coli em um pinguim-deMagalhães com pododermatite em grau III, desenvolvida durante período de cativeiro para reabilitação. O animal foi à óbito por morte súbita, observando-se ao exame necroscópico extensas lesões em coxins plantares, além de alterações teciduais em pulmões, sacos aéreos e fígado, de onde houve isolamento de $E$. coli. Ao exame histopatológico pode-se observar presença de bactérias nestes tecidos, além de colônias bacterianas intravasculares na epiderme de um dos coxins plantares.
\end{abstract}

Palavras chave: Colibacilose, pododermatite, pinguim

\section{Sepsis by Escherichia coli in Penguin (Spheniscus Magellanicus) with bumblefoot: Case report}

\begin{abstract}
Pododrematite, or bumblefoot, is a limb condition limiting the rehabilitation of penguins. The study reports a case of sepsis by Escherichia coli in a Magellanic penguin with grade III pododermatitis, developed during a period of captivity for rehabilitation. The animal died due to sudden death, with necroscopic examination being extensive lesions on foot pad, as well as tissue changes in lungs, air sacs and liver, from which there was isolation of E. coli. Histopathological examination shows the presence of bacteria in these tissues, as well as intravascular bacterial colonies in the epidermis of one of the foot pad.
\end{abstract}

Keyword: Colibacilosis, pododermatitis, penguin

\section{Sepsis por Escherichia coli en pinguino (Spheniscus Magellanicus) con bumblefoot: Reporte de un caso}

RESUMEN. Pododermatitis, o bumblefoot, es una afección podal limitante a la rehabilitación de los pingüinos. El estudio relata un caso de sepsis por Escherichia coli en un pingüino de Magallanes con pododermatitis grado III, desarrollada durante período de cautiverio para rehabilitación. Se produjo una muerte súbita, observándose al examen necroscópico extensas lesiones en las almohadillas de la pata, además de alteraciones en los pulmones, bolsas aéreas e hígado, de donde hubo aislamiento de E. coli. El examen histopatológico mostró la presencia de bacterias en estos tejidos, así como colonias bacterianas intravasculares en la epidermis de una de las almohadillas

Palabras clave: Colibacilosis, pododermatitis, pinguino 


\section{Introdução}

Entre as doenças de maior ocorrência em pinguins em cativeiro está o bumblefoot, ou pododermatite (Clarke and Kerry, 1993), uma síndrome de múltiplas etiologias, que em aves é um termo genérico utilizado para designar qualquer processo inflamatório nos membros posteriores (Shane, 2005, Hocking et al., 2008). Esta enfermidade é descrita em diferentes espécies, porém tem especial relevância em aves aquáticas (Fowler and Cubas, 2001, Cooper, 2008, Cubas et al., 2014, Clarke and Kerry, 1993).

Em pinguins o principal fator predisponente para o desenvolvimento da pododermaite é o traumatismo abrasivo associado ao sedentarismo, alto peso corporal e permanência sobre pisos firmes do cativeiro (Clarke and Kerry, 1993, Fowler and Cubas, 2001, Girling, 2003, Cubas et al., 2014). Todavia, quaisquer outros fatores que levem à quebra da barreira epitelial devem ser considerados, uma vez que favorecem a colonização microbiana, tanto por microrganismos com potencial patogênico que compõe a microbiota da pele e dos tratos digestório e respiratório, quanto por microorganismos presentes no ambiente (Cubas et al., 2014). Existem diversas espécies de bactérias relacionadas à infecção pós-trauma no bumblefoot (Ritchie et al., 1997, Cooper, 2008, Girling, 2003); porém ainda são poucos os estudos que referenciam a participação de fungos na patogenia da síndrome, havendo poucos relatos de pododermatite micótica (Stoute et al., 2009).

A síndrome bumblefoot é de alta morbidade em pinguins em cativeiro, acarretando lesões progressivas que vão desde o enrijecimento ou tumefação digitais até abscessos crônicos com afecção do tecido adjacente, podendo evoluir para septicemia e óbito quando ocorrem em grau mais elevado (Clarke and Kerry, 1993, Shane, 2005, Hocking et al., 2008, Cooper, 2008). A infecção por E. coli, em particular, é extremamente importante pela sua capacidade de gerar quadro de septicemia (Marietto Gonçalves et al., 2007). Em associação à Klebsiella sp., esta bactéria foi descrita como responsável pela maioria dos casos de enterite em pinguins de cativeiro (Clarke and Kerry, 1993). Do mesmo modo que já foi isolada, juntamente com Staphylococcus sp. em diversos casos de artrite supurada em frangos, causando preocupação em aviários de produção (Fallavena et al., 1991, Segabinazi et al., 2005). A E. coli faz parte da microbiota entérica de mamíferos e de muitas espécies de aves, e é um bastonete curto, Gram negativo, não esporulado, aeróbio ou anaeróbio facultativo, móvel ou imóvel (Bier, 1988).

A colisepticemia é uma infecção generalizada severa causada por E. coli, que apresenta como sintomatologia início súbito, postura sonolenta, eriçamento de penas e anorexia, podendo ocorrer poliúria, diarreia e morte súbita (Marietto Gonçalves et al., 2007). Em função da importância da $E$. coli como patógeno e da alta morbidade do bumblefoot em pinguins, o presente estudo objetivou relatar um caso de colisepticemia com infecção primária em coxim plantar em um pinguim-de-Magalhães (Spheniscus magellanicus) mantido em cativeiro para período de reabilitação.

\section{Relato de caso}

Um pinguim-de-Magalhães juvenil fêmea apresentando caquexia e bumblefoot em grau III em ambos os coxins plantares (Figura 1) foi a óbito por morte súbita em centro de recuperação. O animal havia sido encontrado em monitoramento realizado na orla marítima, sem alterações podais, desenvolvendo bumblefoot durante período de reabilitação. A ave foi submetida à necropsia, e durante o exame necroscópico foram observadas alterações macroscópicas teciduais em órgãos internos, bem como as lesões em coxins plantares foram avaliadas ao corte quanto à extensão. Coletaramse swabs de sacos aéreos e fragmentos de: traqueia, siringe, pulmões, fígado, baço, rins e coxim plantar, tanto para avaliação histopatológica quanto microbiológica.

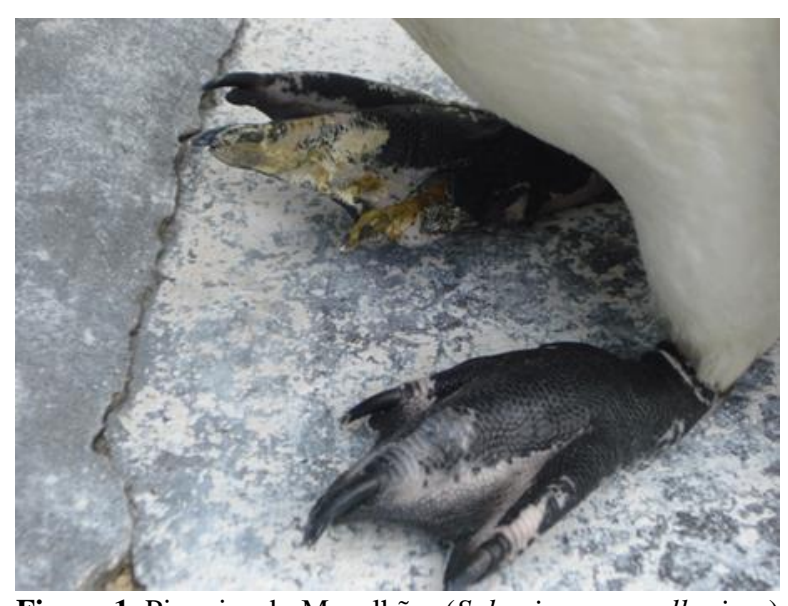

Figura 1. Pinguim-de-Magalhães (Spheniscus magellanicus) com pododermatite grau III em ambos os membros. 
No Setor de Patologia do Laboratório Regional de Diagnósticos da Faculdade de Veterinária da Universidade Federal de Pelotas (LRD-FVUFPel) foi realizado o exame histopatológico dos tecidos obtidos à necropsia pela fixação em formol a $10 \%$, inclusão em parafina, e coloração de Hematoxilina-eosina (HE). As lâminas foram observadas em sub-macroscopia e microscopia para exame de alterações teciduais e avaliação da presença de microrganismos nos tecidos.

O material coletado para avaliação microbiológica foi imediatamente encaminhado para processamento no Laboratório de Doenças Infecciosas, nos Setores de Bacteriologia e de Micologia da FV-UFPel. No Setor de Bacteriologia as amostras foram semeadas em duplicata pela técnica de esgotamento em placas de petri contendo ágar sangue a 5\% de sangue ovino e ágar MacConkey, incubadas a $37^{\circ} \mathrm{C}$ por 24-48 horas. Após esse período foi realizado repique para obtenção das culturas puras. Foi realizado exame direto das colônias através da coloração de Gram, e também foram realizadas provas bioquímicas, como teste de CAMP, teste de oxidação de carboidratos, provas da esculina, da gelatina, da ureia, nitrato e SIM. Além do bioquimismo foram avaliadas características como capacidade de hemólise, produção de catalase e coagulase. No Setor de Micologia as amostras foram semeadas pela técnica de esgotamento em placas de petri contendo ágar Sabouraud dextrose acrescido de cloranfenicol e encubadas a $37^{\circ} \mathrm{C}$ por 14 dias.

\section{Discussão}

Ao exame necroscópico observou-se hepatomegalia e fígado friável, além de atrofia esplênica e opacidade de sacos aéreos. Ao exame do coxim plantar constatou-se presença de úlcera profunda e lesão na articulação do tornozelo em ambos os membros. Não houve isolamento de fungos de nenhuma das amostras coletadas. Ao exame bacteriológico isolou-se $E$. coli de coxim plantar, saco aéreo, pulmão e fígado (Figura 2). A confirmação da espécie ocorreu pelas provas bioquímicas, apresentando motilidade, produção de indol e lisina-descarboxilase, fermentação de glicose e sacarose e produção de gás. Apesar de a E. coli ser habitante do trato gastrointestinal, a colibacilose é uma doença de manifestação extra intestinal, na qual um dos principais quadros encontrados é a morte súbita por colisepticemia (Barnes, 1997), conforme encontrado no pinguimde-Magalhães, que foi a óbito por morte súbita e apresentou alteração macroscópica em tecidos dos quais obteve-se isolamento de E. coli.

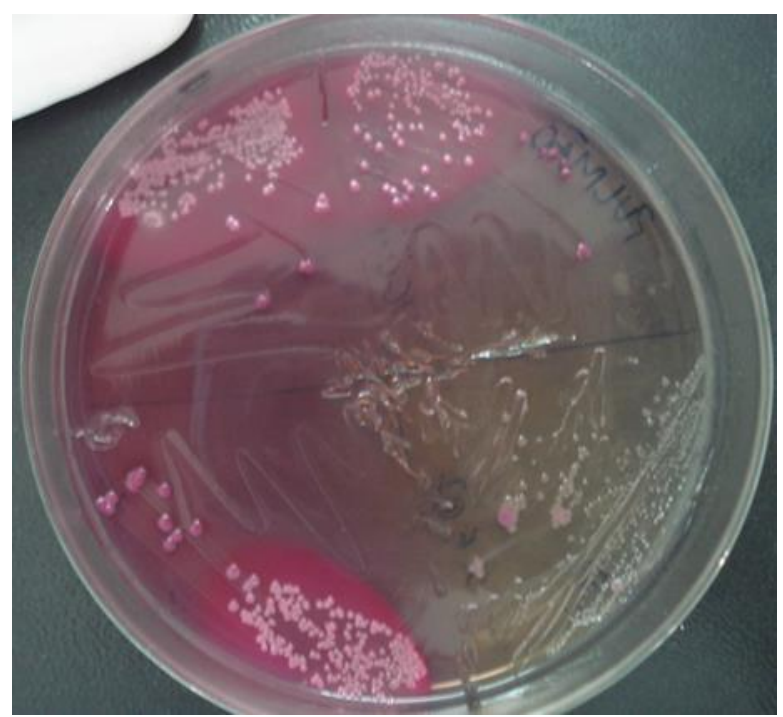

Figura 2. Isolamento de Escherichia coli em coxim plantar, fígado, pulmão e saco aéreo de pinguim-de-Magalhães (Spheniscus magellanicus) com septicemia decorrente de pododermatite grau III.

Ao exame histopatológico de coxim direito observou-se perda da camada de rete ridges, presença de ulceração até a camada da epiderme, colônias bacterianas intralesionais e vasculite em vasos da derme (Figura 3). No coxim plantar esquerdo encontrou-se exuberante descamação da camada de queratina e vaso sanguíneo na derme com colônias bacterianas (Figura 4).

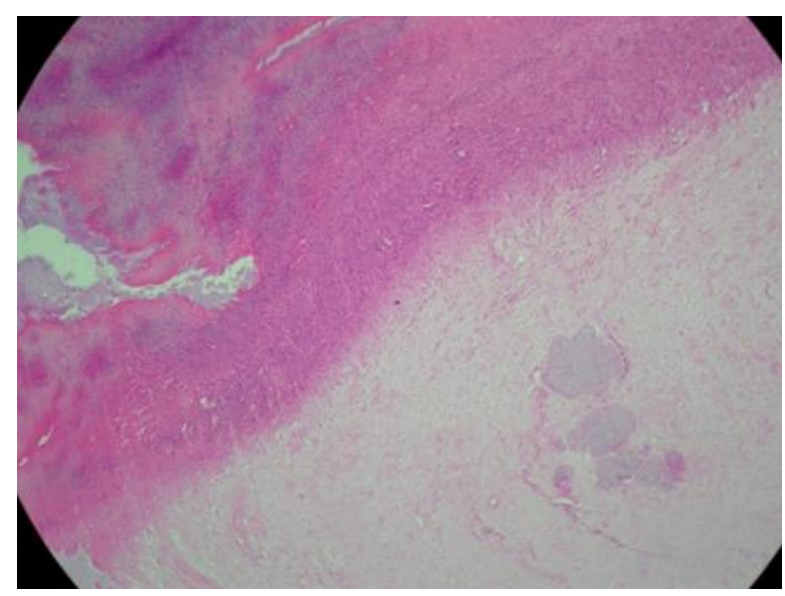

Figura 3. Coxim plantar direito de pinguim-de-Magalhães (Spheniscus magellanicus) com pododermatite grau III, apresentando perda da camada de rete ridges e colônias bacterianas intradérmicas. Exame histopatológico, coloração PAS, aumento de $400 x$.

As lesões encontradas em ambos os coxins indicam a ocorrência de pododermatite em grau III, o grau mais elevado da síndrome, de pior prognóstico e que tende, pelo curso progressivo do bumblefoot, a evoluir para septicemia (Cooper, 
2008), conforme ocorreu com a ave estudada. A presença de colônias bacterianas no interior de vaso sanguíneo da derme em coxim do qual foi isolada cultura pura de E. coli indica a disseminação do microrganismo por via hematógena a partir da lesão em coxim plantar, confirmando desta forma a infecção como consequência da pododermatite.

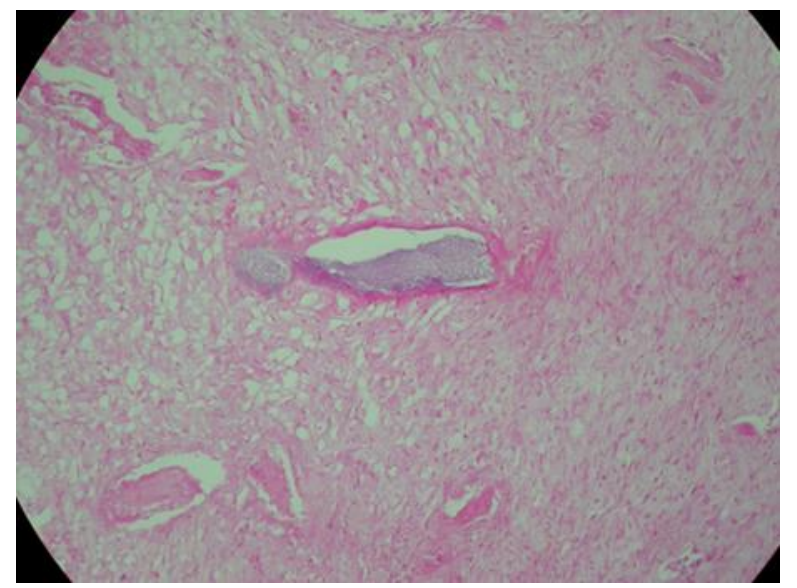

Figura 4. Coxim plantar esquerdo de pinguim-de-Magalhães (Spheniscus magellanicus) com grau III de pododermatite. Presença de colônia bacteriana em vaso da derme. Exame histopatológico, coloração PAS, aumento de 400x.

A histopatologia do fígado, órgão do qual também foi isolada a enterobactéria em cultura pura, demonstrou presença de colônias bacterianas em lesões com diferentes tempos de infecção, onde a mais antiga foi evidenciada pela discreta proliferação de tecido conjuntivo (iguras 5 e $\underline{6}$ ).

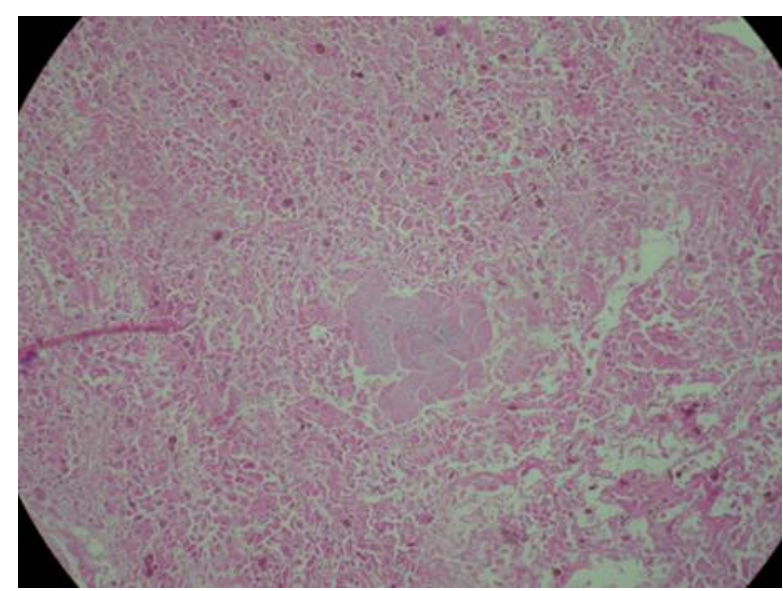

Figura 5. Lesão hepática decorrente de colisepticemia em pinguim-de-Magalhães (Spheniscus magellanicus) com grau III de pododermatite. Exame histopatológico, coloração PAS, aumento 400x.

A E. coli faz parte do grupo das enterobactérias, que são habitantes do trato gastrointestinal dos animais, compondo a biota residente ou transitória, ou ainda servindo como agentes de infecção. Apesar de diversos destes microrganismos poderem ser encontrados em diferentes habitats, geralmente sua origem é entérica (Bier, 1988) e Anvisa (2004). Em 95\% dos casos de infecção por enterobactérias encontram-se as espécies clássicas, entre as quais se destaca a E. coli (Anvisa, 2004). Por manteremse em estação por tempo prolongado em área seca, pinguins debilitados acabam tendo contato com sua própria excreta, que pode configurar como contaminante de feridas. Aves com bumblefoot apresentam quebra da barreira natural da pele, o que favorece a contaminação por microrganismos presentes no ambiente (Cubas et al., 2014), tornando-as, nesta situação, propensas a colibacilose.

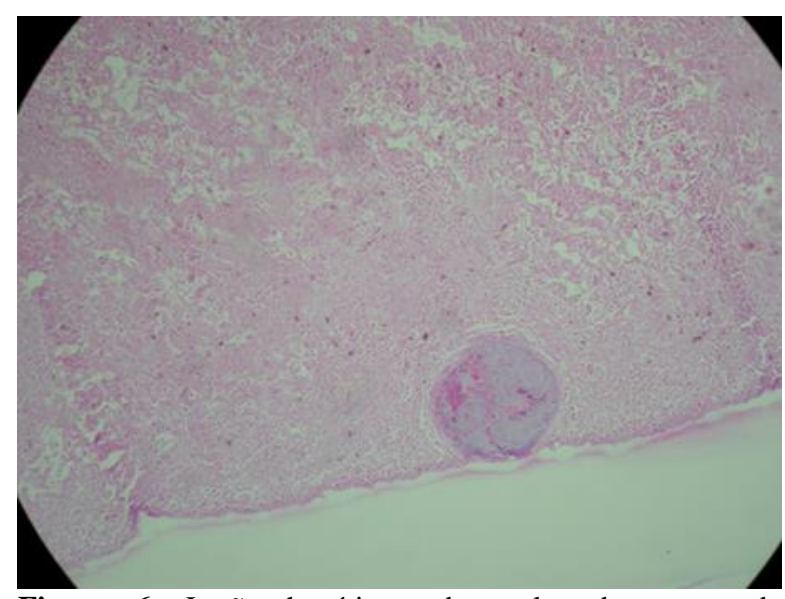

Figura 6. Lesão hepática subcapsular decorrente de colisepticemia em pinguim-de-Magalhães (Spheniscus magellanicus) com grau III de pododermatite. Exame histopatológico, coloração PAS, aumento 400x.

\section{Considerações Finais}

O presente trabalho documenta um caso de colisepticemia em pinguim-de-Magalhães, tendo como foco primário bumblefoot em grau III em ambos os coxins plantares. E salienta a importância da síndrome na reabilitação destas aves.

\section{Agradecimentos}

Centro de Recuperação de Animais Marinhos (CRAM-FURG), Coordenação de Aperfeiçoamento Pessoal de Nível Superior (CAPES) e Conselho Nacional de Desenvolvimento Científico e Tecnológico (CNPq)

\section{Referências Bibliográficas}

ANVISA - Agência Nacional de Vigilância Sanitária. Deteç̧ão e Identificação de 
Bactérias de Importância Médica, 2004. Módulo V. Disponível em www.anvisa.gov.br

Barnes, H. 1997. Collibacillosis. In: Calnek, B. W., Barnes, H. J., Beard, C. W. \& McDoulgald (eds.) Diseases of poultry. The Iowa State University Press, Iowa, USA.

Bier, O. 1988. Microbiologia e imunologia. Melhoramentos, São Paulo, Brasil.

Clarke, J. R. \& Kerry, K. R. 1993. Diseases and parasites of penguins. Korean Journal of Polar Research, 4, 79-96.

Cooper, J. E. 2008. Birds of prey: health and disease. John Wiley \& Sons, USA.

Cubas, Z. S., Silva, J. C. R. \& Dias, J. L. C. 2014. Tratado de animais selvagens-medicina veterinária. Editora Roca.

Fallavena, L. C. B., Salle, C. T. P., Moraes, H. L. d. S., Krahl, M., Reali, E. H., Santos, G. P., Coutinho, A. \& Franco, J. L. K. 1991. Problemas locomotores em frangos de três linhagens do tipo corte: I. Aspectos clínicos, ocorrência de discondroplasia tibial e encurvamento do tibiotarso. Arquivo Brasileiro de Medicina Veterinária e Zootecnia, 43, 337-47.

Fowler, M. E. \& Cubas, Z. S. 2001. Biology, medicine, and surgery of South American wild animals. Wiley Online Library, USA.

Girling, S. 2003. Veterinary Nursing of Exotic Species. Blackwell publishing, USA.

Hocking, P. M., Mayne, R. K., Else, R. W., French, N. A. \& Gatcliffe, J. 2008. Standard European footpad dermatitis scoring system for use in turkey processing plants. World's Poultry Science Journal, 64, 323-328.

Marietto Gonçalves, G. A., Lima, E. T., Sequeira, J. L. \& Andreatti Filho, R. L. 2007. Colisepticemia em Papagaio verdadeiro (" Amazona aestiva")-Relato de Caso. Revista Brasileira de Saúde e Produção Animal, 8, 5660.

Ritchie, B. W., Hsarrison, G. J., Zantop, D. \& Harrison, L., R,. 1997. Avian medicine: principles and application, abridged edition. Idaho Falls, ID: Wingers Publishing, USA.

Segabinazi, S. D., Flôres, M. L., Barcelos, A. S., Jacobsen, G. \& Eltz, R. D. 2005. Bactérias da família Enterobacteriaceae em Alphitobius diaperinus oriundos de granjas avícolas dos Estados do Rio Grande do Sul e Santa Catarina, Brasil. Acta Scientiae Veterinariae, 33, 51-55.

Shane, S. M. 2005. Handbook on poultry diseases. American Soybean Association, USA.

Stoute, S. T., Bickford, A. A., Walker, R. L. \& Charlton, B. R. 2009. Mycotic pododermatitis and mycotic pneumonia in commercial turkey poults in northern California. Journal of Veterinary Diagnostic Investigation, 21, 554557.

Article History:

Received 16 June 2017

Accepted 31 July 2017

Available on line 16 August 2017

License information: This is an open-access article distributed under the terms of the Creative Commons Attribution License 4.0, which permits unrestricted use, distribution, and reproduction in any medium, provided the original work is properly cited. 